\title{
Association of rat thoracic aorta dilatation by astragaloside IV with the generation of endothelium-derived hyperpolarizing factors and nitric oxide, and the blockade of $\mathrm{Ca}^{2+}$ channels
}

\author{
GUANYING HU, XIXIONG LI, SANYIN ZHANG and XIN WANG
}

Basic Medical College, Chengdu University of Traditional Chinese Medicine, Chengdu, Sichuan 611137, P.R. China

Received November 26, 2015; Accepted April 11, 2016

DOI: $10.3892 /$ br. 2016.680

\begin{abstract}
The aim of the present study was to elucidate the roles of endothelium-derived hyperpolarizing factors (EDHFs) and nitric oxide (NO) in mediating the vasodilatation response to astragaloside IV and the effects of astragaloside IV on voltage-dependent $\mathrm{Ca}^{2+}$ channels and receptor-operated $\mathrm{Ca}^{2+}$ channels in rat thoracic aortic rings precontracted with potassium chloride $(\mathrm{KCl} ; 60 \mathrm{mM})$ or phenylephrine (PHE; $1 \mu \mathrm{M})$. The results showed that astragaloside IV $\left(1 \times 10^{-4}-3 \times 10^{-1} \mathrm{~g} / \mathrm{l}\right)$ concentration-dependently relaxed the contraction induced by $\mathrm{KCl}(10-90 \mathrm{mM})$ or PHE $\left(1 \times 10^{-9}-3 \times 10^{-5} \mu \mathrm{M}\right)$ and inhibited concentration-contraction curves for the two vasoconstrictors in the aortic rings. Preincubation with $\mathrm{N}^{\omega}$-nitro-L-arginine methyl ester (L-NAME, $100 \mu \mathrm{M}$ ) significantly attenuated astragaloside IV-induced relaxation in the endothelium-intact and -denuded arterial rings precontracted with PHE. Astragaloside IV, following preincubation with L-NAME $(100 \mu \mathrm{M})$ plus indomethacin $(10 \mu \mathrm{M})$, exerted vasodilatation, which was depressed by tetraethtylamine $(1 \mathrm{mM})$ and propargylglycine $(100 \mu \mathrm{M})$, but not by carbenoxolone $(10 \mu \mathrm{M})$, catalase $(500 \mathrm{U} / \mathrm{ml})$ or proadifen hydrochloride $(10 \mu \mathrm{M})$. The action mode of astragaloside IV was evident in comparison to nifedipine. Inhibition of PHE-induced contraction by
\end{abstract}

Correspondence to: Professor Sanyin Zhang, Basic Medical College, Chengdu University of Traditional Chinese Medicine, 1166 Liutai Road, Chengdu, Sichuan 611137, P.R. China

E-mail: tcmzsy@126.com

Abbreviations: AM, Astragalus memeranaceus; NO, nitric oxide; $\mathrm{PGI}_{2}$, prostanoids; EDHFs, endothelium-derived hyperpolarizing factors; PHE, phenylephrine; $\mathrm{KCl}$, potassium chloride; iNOS, inducible nitric oxide synthase; sGC, soluble guanylate cyclase; cGMP, cyclic guaosine monophosphate; VSMC, vascular smooth muscle cells; Ach, acetylcholine; L-NAME, $\mathrm{N}^{\omega}$-nitro-L-arginine methyl ester; TEA, tetraethtylamine; CBX, carbenoxolone; PPG, propargylglycine; CAT, catalase; SKF525A, proadifen hydrochloride; NOS, nitric oxide synthase; COX, cyclooxygenase; $\mathrm{H}_{2} \mathrm{~S}$, hydrogen sulfide

Key words: astragaloside IV, thoracic aorta, dilatation, nitric oxide, endothelium derived-hyperpolarizing factor, $\mathrm{Ca}^{2+}$ astragaloside IV (100 mg/l) was more potent compared to inhibition of $\mathrm{KCl}$-induced contraction, while inhibition of $\mathrm{KCl}$-induced contraction by nifedipine $(100 \mathrm{mg} / \mathrm{l})$ was more potent compared to inhibition of PHE-induced contraction by nifedipine $(100 \mathrm{mg} / \mathrm{l})$. In addition, the combination of astragaloside IV and nifedipine exhibited synergistic and additive inhibitory effects on contraction evoked by $\mathrm{KCl}$, which was similar to PHE. In conclusion, astragaloside IV, as a $\mathrm{Ca}^{2+}$ antagonist, relaxes the vessels through the blockade of superior receptor-operated $\mathrm{Ca}^{2+}$ and inferior voltage-dependent $\mathrm{Ca}^{2+}$ channels, which modulate NO from vascular endothelial cells and vascular smooth muscle cells, and EDHFs including $\mathrm{K}^{+}$and hydrogen sulfide.

\section{Introduction}

Astragaloside IV (Fig. 1), a small molecular saponin, is usually selected as one of the marker compounds for chemical assessment and standardization of Astragalus membranaceus (AM) and its products (1). Numerous studies have indicated that astragaloside IV causes multiple pharmacological effects, including antioxidant (2), anti-inflammatory (3), antitumor (4), anti-fibrotic (5), antivirus (6), anti-radiation (7) and anti-scar (8) effects, and promotes angiogenesis (9). Additionally, astragaloside IV can also relax the aortic artery, which is possibly the pivotal mechanism for why AM, at present, has been widely used to treat numerous disorders, including cardiovascular diseases, in traditional Chinese medicine $(10,11)$.

The vascular smooth muscle contracts in response to the activation on voltage-dependent $\mathrm{Ca}^{2+}$ and receptor-operated $\mathrm{Ca}^{2+}$ channels $(12,13)$, whilst vascular endothelial cells have an important role in monitoring tension by synthesizing and secreting various bioactive substances, particularly dilating factors, such as nitric oxide (NO) (14), prostanoids $\left(\mathrm{PGI}_{2}\right)(15)$ and endothelium-derived hyperpolarizing factors (EDHFs) $(16,17)$. A number of studies have suggested that astragaloside IV relaxed aortic vessels in a concentration-dependent manner. The comprehensive mechanisms were associated with endothelium-dependence through the $\mathrm{NO}$ and $\mathrm{PGI}_{2}$ pathways, and inhibiting extracellular $\mathrm{Ca}^{2+}$ influx and intracellular $\mathrm{Ca}^{2+}$ stores release (18-20). However, this mechanism has not been reported on EDHFs mediating astragaloside IV-induced vasodilatation and influences of astragaloside IV on voltage-dependent $\mathrm{Ca}^{2+}$ channels and receptor-operated $\mathrm{Ca}^{2+}$ channels. Additionally, 
studies have reported the relaxation response to astragaloside IV presenting in the endothelium-denuded (E-) aortic rings; however, the relative mechanisms remain to be elucidated. The expression levels of inducible NO synthase (iNOS) and cyclic guaosine monophosphate (cGMP) were reported to be markedly increased when AM was acting in cultured vascular smooth muscle cells (VSMC) (21), suggesting that the direct action target of AM-induced vasodilatation is vascular smooth muscle through the NO-soluble guanylate cyclase (sGC) signaling pathway without endothelium mediating. These results propose a hypothesis that astragaloside IV, as a major constituent extracted from AM, may produce relaxant abilities through the generation of NO from the vascular smooth muscle system.

Thus, the present study was designed to elucidate the effects of EDHFs and the NO from VSMC on astragaloside IV-induced relaxation and further explore the effects of astragaloside IV on the voltage-dependent $\mathrm{Ca}^{2+}$ and receptor-operated $\mathrm{Ca}^{2+}$ channels.

\section{Materials and methods}

Animals. Healthy male Sprague-Dawley rats weighing 180-220 g, were purchased from Dashuo Biotechnology Co., Ltd. (Chengdu, Sichuan, China). All the rats were raised in cages with commercial solid foods and tap water available under identical conditions. The temperature was maintained at $25 \pm 11^{\circ} \mathrm{C}$, the humidity at $50 \pm 5 \%$ and the artificial illumination was for $12 \mathrm{~h}$ (light period 7:00 a.m.-7:00 p.m.). All the experimental procedures were performed under the guidelines of the Management Committeef from Chengdu University of Traditional Chinese Medicine (Chengdu, Sichuan, China).

Chemicals and reagents. Astragaloside IV (chemical structure in Fig. 1, purity 98\%; 3-O- $\beta$-D-xylopyranosyl-6-O- $\beta$ -D-glucopyranosyl-cycloastragenol) was purchased from Sichuan Weikeqi Biotech Co., Ltd. (Chengdu, Sichuan, China). Nifedipine was obtained from Shanxi Taiyaun Pharmaceutic Co., Ltd. (Taiyuan, Shanxi, China). Phenylephrine (PHE), acetylcholine (Ach), $\mathrm{N}^{\omega}$-nitro-L-arginine methyl ester (L-NAME), indomethacin, tetraethtylamine (TEA), carbenoxolone (CBX), propargylglycine (PPG), catalase (CAT) and proadifen hydrochloride (SKF525A) were purchased from Sigma-Aldrich (St. Louis, MO, USA). The other inorganic salts were provided by Chengdu Kelong Chemical Reagent (Chengdu, Sichuan, China).

The stock solution of astragaloside IV in dimethyl sulfoxide (DMSO; $10 \mathrm{~g} / \mathrm{l}$ ) was stored at $-20^{\circ} \mathrm{C}$ and used within 1 week. Indomethacin was dissolved in $95 \%$ ethanol and protected from light with aluminum foil. The highest concentrations of DMSO and ethanol were $\leq 0.01 \%$ in each of the chambers. Other chemicals and reagents were dissolved in distilled water and diluted with Krebs-Henseleit (K-H) solution prior to use. In the present study, all the concentrations noted were the final concentration in the bath chambers.

Preparation of thoracic aorta rings. Rats underwent cervical vertebrae dislocation, and subsequently the thoracic aortic artery was removed rapidly from the carotid artery and immediately placed into $4^{\circ} \mathrm{C}$ oxygenated $\mathrm{K}-\mathrm{H}$ solution in which the aorta was cleaned of residual fat and connective tissue

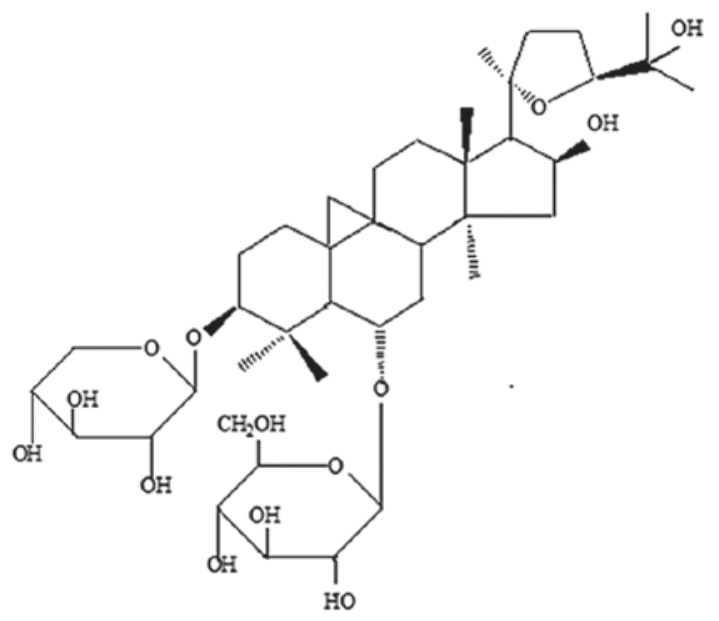

Figure 1. Chemical structure of astragaloside IV (C41H68O14; molecular weight 784).

and separated 3-5 $\mathrm{mm}$ in length. Aortic rings were mounted with two stainless steel hooks and suspended in the $10-\mathrm{ml}$ organ chambers containing K-H solution ( $\mathrm{pH} 7.4$ ), which was composed of $118.4 \mathrm{mM} \mathrm{NaCl}, 4.7 \mathrm{mM}$ potassium chloride (KCl), $2.5 \mathrm{mM} \mathrm{CaCl}_{2}, 1.2 \mathrm{mM} \mathrm{KH}_{2} \mathrm{PO}_{4}, 1.2 \mathrm{mM} \mathrm{MgSO}_{4}$, $25.0 \mathrm{mM} \mathrm{NaHCO}, 11.0 \mathrm{mM}$ glucose and $0.03 \mathrm{mM}$ ethylenediaminetetraacetic acid, aerated with $5 \% \mathrm{CO}_{2}$ and maintained at $37^{\circ} \mathrm{C}$. The isometric tension of the aortic rings was monitored by four-channels of physiological force transducers. All the rings were stretched to $1 \mathrm{~g}$ resting tension in normal K-H solution for $1 \mathrm{~h}$, and contracted repeatedly with $60 \mathrm{mM} \mathrm{KCl}$ or $1 \mu \mathrm{M}$ PHE successively. The rings were allowed to rest until the baseline was restored following each contraction. When the contraction was stable and the concentration-contraction curve to $\mathrm{KCl}$ or PHE was repeatable, the effects of the drugs to be tested were observed. The endothelium in each arterial ring was denuded mechanically by forceps cannulating the lumen of the ring and gently rolling the vessel on the moist absorbent gauze. The endothelium was removed judging by the $<10 \%$ relaxant response to $10 \mu \mathrm{M}$ Ach subsequent to precontraction of the arterial rings with $1 \mu \mathrm{M}$ PHE.

Effects of astragaloside IV on basal tension. When the thoracic aortic rings were only with $1 \mathrm{~g}$ resting tension in the absence of $\mathrm{KCl}$ or PHE, cumulative concentrations of astragaloside IV $(0.1,0.3,1,3,10,30,100$ and $300 \mathrm{mg} / \mathrm{l})$ and equal doses of DMSO were added to the chamber, respectively. The vascular response to each concentration of astragaloside IV or DMSO was allowed to develop until the stable plateau was reached.

Effects of astragaloside IV on contraction. Two different experiments was performed. In one experiment, when the contraction response to $60 \mathrm{mM} \mathrm{KCl}$ or $1 \mu \mathrm{M}$ PHE was repeated and the last contraction was maintained steadily, the different concentrations of astragaloside IV were added stepwise in a cumulative manner. The maximal contraction induced by $60 \mathrm{mM} \mathrm{KCl}$ or $1 \mu \mathrm{M}$ PHE was taken as $100 \%$. In the second experiment, a concentration-contraction curve for $\mathrm{KCl}(10-90 \mathrm{mM})$ or PHE $\left(1 \times 10^{-9}-3 \times 10^{-5} \mu \mathrm{M}\right)$ was constructed, respectively. When successive curves were repeatable, the 
arterial rings were preincubated with astragaloside IV prior to a repeat of the reconstruction of the contractile curves for the two cases.

Effects of inhibitors and denudation on astragaloside $I V$-induced relaxation. To study the roles of EDHF and NO, effects of relative inhibitors on astragaloside IV-induced relaxation in endothelium-intact $(\mathrm{E}+)$ arterial rings were analyzed. When the contraction induced by $1 \mu \mathrm{M}$ PHE was repeatable and the last contraction was sustained, the rings were respectively preincubated with NO synthase inhibitor L-NAME $(100 \mu \mathrm{M})$, and L-NAME $(100 \mu \mathrm{M})$ together with cyclooxygenase inhibitor indomethacin $(10 \mu \mathrm{M})$, $\mathrm{Ca}^{2+}$-dependent $\mathrm{K}^{+}$channels blocker TEA (1 mM), gap junction blocker CBX $(10 \mu \mathrm{M})$, cystathionine $\gamma$-lyse inhibitor DL-PPG $(100 \mu \mathrm{M})$, CAT $(500 \mathrm{U} / \mathrm{ml})$, or cytochrome P450 monoamine oxidase inhibitor proadifen hydrachloride (SKF525A, $10 \mu \mathrm{M}$ ) for $20 \mathrm{~min}$ before astragaloside IV was cumulatively added to the chamber. Regarding the investigation of endothelium-denudation, experiments to analyze the effects of astragaloside IV were conducted in the E- arterial rings in the presence or absence of $100 \mu \mathrm{M}$ L-NAME following a repeatable and sustained contraction.

Effects of astragaloside IV on $\mathrm{Ca}^{2+}$ channels. To measure the effects of astragaloside IV on $\mathrm{Ca}^{2+}$ channels, contraction induced by $60 \mathrm{mM} \mathrm{KCl}$ or $1 \mu \mathrm{M}$ PHE was compared when the rings were respectively preincubated with astragaloside IV (100 mg/l), nifedipine (100 mg/l), or astragaloside IV plus nifedipine for $20 \mathrm{~min}$ after a repeatable and sustained contraction with $60 \mathrm{mM} \mathrm{KCl}$ or $1 \mu \mathrm{M}$ PHE.

Statistical analysis. All the values are expressed as mean \pm standard deviation. Relaxant responses were expressed as the percentage according to the maximal contractile tension induced by $\mathrm{KCl}(60 \mathrm{mM})$ or PHE $(1 \mu \mathrm{M})$. To evaluate the potency of testing drugs, values of $E_{\max }$ and $\mathrm{p} D 2$ (negative logarithms of value $\mathrm{EC}_{50}$ which denotes the concentration of drugs induced $50 \%$ of maximal effects) were calculated. The data were analyzed using the Student's t-test or Mann-Whitney $\mathrm{U}$ test when appropriate. $\mathrm{P}<0.05$ was considered to indicate a statistically significant difference.

\section{Results}

Effects of astragaloside $I V$ in thoracic aortic rings at $1 \mathrm{~g}$ resting tension. In thoracic aortic rings with $1 \mathrm{~g}$ resting tension, adding cumulative concentrations of astragaloside IV $\left(1 \times 10^{-4}-3 \times 10^{-1} \mathrm{~g} / \mathrm{l}\right)$ had no significant vasomotor actions on the baseline ( $\mathrm{P}>0.05$, compared with the vehicle control).

Effects of astragaloside IV on $\mathrm{KCl}$ or PHE-induced contraction. Astragaloside IV produced a concentration-dependent relaxation in arterial rings precontracted with $60 \mathrm{mM} \mathrm{KCl}$ or $1 \mu \mathrm{M}$ PHE. When the rings were exposed to $\mathrm{KCl}$, the astragaloside IV-elicited maximal relaxation magnitude $\left(E_{\max }\right)$ was $57.60 \pm 9.55 \%$ and the sensitivity $(\mathrm{p} D 2)$ was $0.79 \pm 0.18$. When they were exposed to PHE, the astragaloside IV (300 mg/l)-elicited $E_{\max }$ was $100.01 \pm 9.64 \%$, and $\mathrm{p} D 2$ was $1.71 \pm 0.27$ (Figs. 2 and $3 \mathrm{~A}$ ).

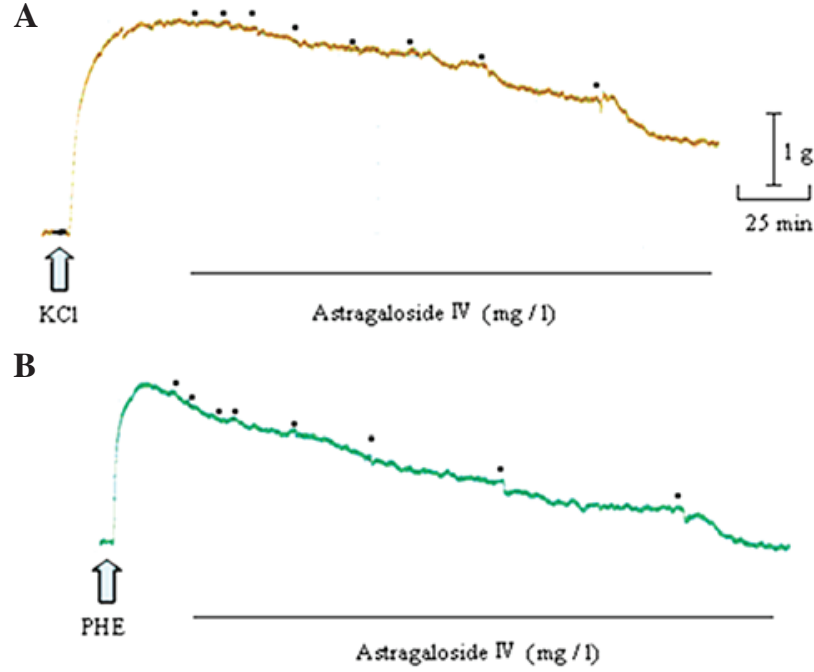

Figure 2. Typical records of the relaxant effects of astragaloside IV on contraction induced by (A) $\mathrm{KCl}(60 \mathrm{mM})$ or (B) PHE $(1 \mu \mathrm{M})$; ・ denotes cumulatively adding astragaloside IV from $1 \times 10^{-4}$ to $3 \times 10^{-1} \mathrm{~g} / 1$. PHE, phenylephrine; $\mathrm{KCl}$, potassium chloride.

In addition, $100 \mathrm{mg} / \mathrm{l}$ astragaloside IV shifted the concentration-contraction curve for $\mathrm{KCl}(10-90 \mathrm{mM})$ or PHE $\left(1 \times 10^{-9}-3 \times 10^{-5} \mathrm{mM}\right)$ nonparallel and downwards to the right. The maximal contraction altitude $\left(E_{\max }\right)$ reduced from $53.88 \pm 10.19$ to $38.42 \pm 8.08 \mathrm{mg} / \mathrm{mm}^{2}$ for $\mathrm{KCl}(\mathrm{P}<0.01)$ and from $31.26 \pm 7.60$ to $11.85 \pm 2.87 \mathrm{mg} / \mathrm{mm}^{2}$ for $\mathrm{PHE}(\mathrm{P}<0.01)$. The values of $\mathrm{p} D 2$ also reduced from $1.54 \pm 0.05$ to $1.47 \pm 0.06$ for $\mathrm{KCl}(\mathrm{P}<0.05)$ and from $7.38 \pm 0.07$ to $7.26 \pm 0.10$ for $\mathrm{PHE}$ $(\mathrm{P}<0.01)$ (Fig. 3B and $\mathrm{C})$.

Effects of astragaloside IV in aortic rings without endothelium. Astragaloside IV also produced concentration-dependently relaxant effects on PHE-evoked contraction in E- arterial rings. Although the values of $E_{\max }$ were significantly decreased $(\mathrm{E}-, 82.81 \pm 3.63 \%, \mathrm{P}<0.01)$, the values of $\mathrm{p} D 2(\mathrm{E}-, 1.45 \pm 0.51$, $\mathrm{P}>0.05)$ were not evidently reduced when compared to that in the E+ rings, respectively (Fig. 4).

Effects of NO on astragaloside IV-induced relaxation in aortic rings with or without endothelium. As shown in Table I, in E+ or E- arterial rings precontracted with PHE, astragaloside IV-elicited relaxation was evidently depressed by $100 \mu \mathrm{M}$ L-NAME in the $E_{\max }(\mathrm{P}<0.01$ for $\mathrm{E}+$ and $\mathrm{E}-)$ and $\mathrm{p} D 2$ values $(\mathrm{P}<0.01$ for $\mathrm{E}+$ and $\mathrm{E}-)$.

Effects of EDHFs on astragaloside IV-induced relaxation. Astragaloside IV showed a dilating response to contraction evoked by PHE, in a concentration-dependent manner, when the arterial rings were in the presence of preincubation with L-NAME $(100 \mu \mathrm{M})$ plus indomethacin $(10 \mu \mathrm{M})$, and the $E_{\max }$ values were markedly reduced $(41.64 \pm 10.52 \%$, $\mathrm{P}<0.01$ ) (Fig. 5A). On the basis of these two inhibitors, arterial rings were preincubated with TEA $(1 \mathrm{mM}), \mathrm{CBX}(10 \mu \mathrm{M}), \mathrm{PPG}$ $(100 \mu \mathrm{M})$, CAT $(500 \mathrm{U} / \mathrm{ml})$ or SKF525A $(10 \mu \mathrm{M})$, respectively, showing that astragaloside IV-induced vasodilatation was not affected by CBX, CAT and SKF525A, but was markedly inhibited by TEA $(\mathrm{P}<0.01)$ and $\mathrm{PPG}(\mathrm{P}<0.05)$ (Fig. $5 \mathrm{~B})$. 
A

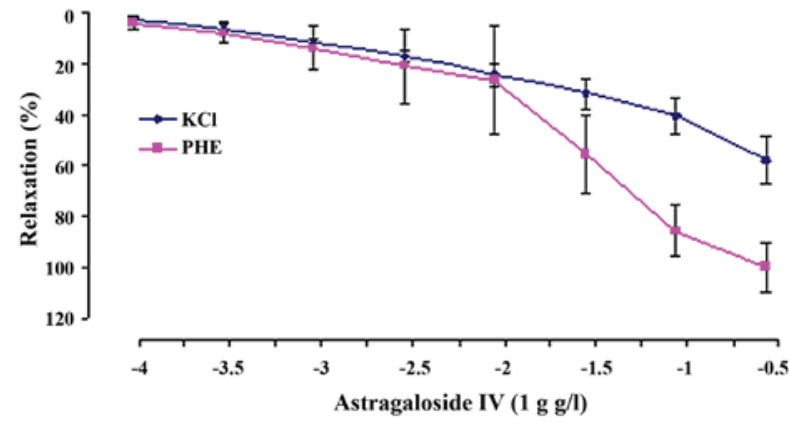

B

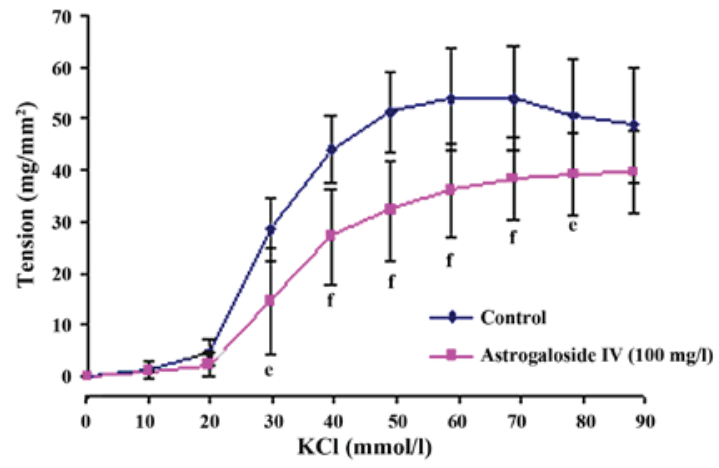

C

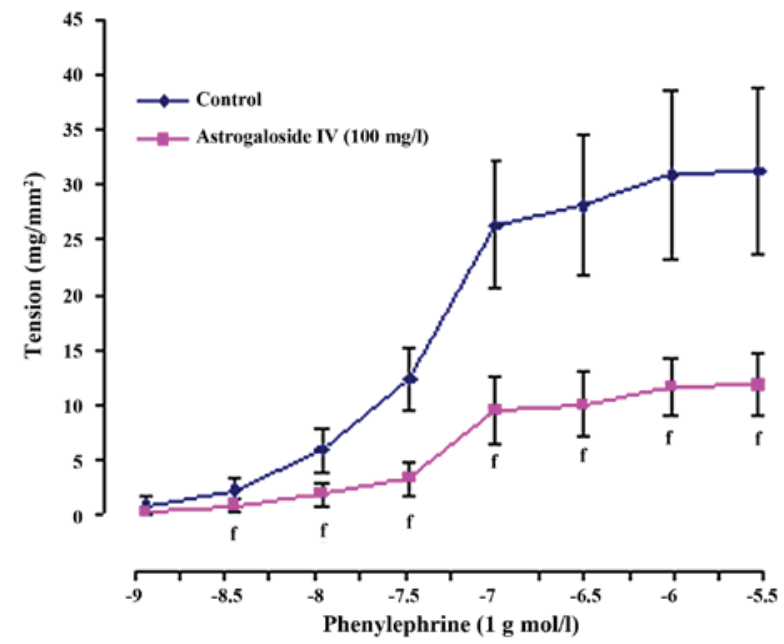

Figure 3. (A) Relaxant effects of astragaloside IV $\left(1 \times 10^{-4}-3 \times 10^{-1} \mathrm{~g} / \mathrm{l}\right)$ on contraction induced by $\mathrm{KCl}(60 \mathrm{mM})$ or PHE $(1 \mu \mathrm{M})$. The alternation of the tension is expressed as percentage of the active contraction induced by $\mathrm{KCl}$ $(60 \mathrm{mM})$ or PHE $(1 \mu \mathrm{M})$. Inhibitory effects of astragaloside IV $(100 \mathrm{mg} / \mathrm{l})$ on the concentration-contraction curve for (B) $\mathrm{KCl}(10-90 \mathrm{mM})$ or (C) PHE $\left(1 \times 10^{-9}-3 \times 10^{-5} \mathrm{mM}\right)$. Data are mean \pm standard deviation $(\mathrm{n}=8) .{ }^{\mathrm{e}} \mathrm{P}<0.05$, ${ }^{\mathrm{f}} \mathrm{P}<0.01$ compared with the vehicle control, respectively. $\mathrm{PHE}$, phenylephrine; $\mathrm{KCl}$, potassium chloride.

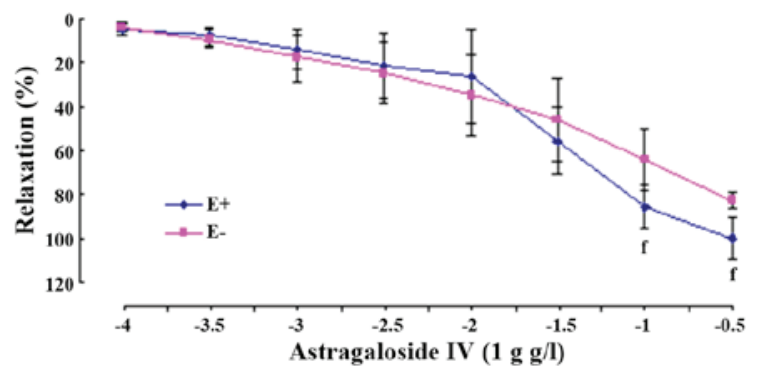

Figure 4. Relaxant effects of astragaloside IV $\left(1 \times 10^{-4}-3 \times 10^{-1} \mathrm{~g} / \mathrm{l}\right)$ on contraction induced by PHE $(1 \mu \mathrm{M})$ in rat E+ or E- aortic rings. The alternation of tension is expressed as percentage of the active contraction induced by PHE $(1 \mu \mathrm{M})$. Data are mean \pm standard deviation $(\mathrm{n}=8) .{ }^{\mathrm{f}} \mathrm{P}<0.01$ compared with $\mathrm{E}-$. PHE, phenylephrine; E+, endothelium-intact; E-, endothelium-denuded.
Comparison of astragaloside IV or nifedipine inhibitory effects on $\mathrm{KCl}$ or PHE-induced contraction. $\mathrm{KCl}$ and PHE-induced contraction were significantly antagonized by $100 \mathrm{mg} / \mathrm{l}$ astragaloside IV and $100 \mathrm{mg} / \mathrm{l}$ nifedipine. However, their action potency were different: Astragaloside IV manifested stronger inhibitory effects on PHE-induced contraction compared to the $\mathrm{KCl}$-induced contraction $\left(\mathrm{KCl} 36.06 \pm 9.00 \mathrm{mg} / \mathrm{mm}^{2}\right.$, PHE $11.57 \pm 2.65 \mathrm{mg} / \mathrm{mm}^{2}, \mathrm{P}<0.01$ ), and nifedipine manifested strongerinhibitoryeffectson KCl-inducedcontractioncompared to the PHE-induced contraction $\left(\mathrm{KCl} 3.89 \pm 1.51 \mathrm{mg} / \mathrm{mm}^{2}\right.$, PHE $\left.6.92 \pm 0.38 \mathrm{mg} / \mathrm{mm}^{2}, \mathrm{P}<0.01\right)$. In the combination treatment, synergistically additive effects were observed and its inhibitory effects on the $\mathrm{KCl}$-induced contraction were similar to that on the PHE-induced contraction (Figs. 6 and 7).

\section{Discussion}

To the best of our knowledge, the present study analyzed for the first time the roles of EDHF and NO in denuding endothelium in vasorelaxation induced by astragaloside IV and further examined the effects of astragaloside IV on the voltage-dependent $\mathrm{Ca}^{2+}$ and receptor-operated $\mathrm{Ca}^{2+}$. The main results were as follows: i) Astragaloside IV produced a concentration-dependent relaxation response to $\mathrm{KCl}$ - or PHE-induced contraction and inhibited the dose-contraction curves for $\mathrm{KCl}$ or PHE in thoracic aortic rings. ii) Astragaloside IV-induced relaxation was attenuated by L-NAME in E+ and E- arterial rings precontracted with PHE. iii) Astragaloside IV, in the preincubation with L-NAME plus indomethacin, exerted vasodilatation that was depressed by TEA and PPG, but was not affected by CBX, CAT or SKF525A. iv) Inhibition of the PHE-induced contraction by astragaloside IV was more potent in comparison to inhibition of the $\mathrm{KCl}$-induced contraction, while inhibition of the $\mathrm{KCl}$-induced contraction by nifedipine was more potent in comparison to inhibition of the PHE-induced contraction. Additionally, combined application of astragaloside IV and nifedipine exhibited synergistic and additive inhibitory effects on the contraction evoked by $\mathrm{KCl}$ similar to PHE. These results added to the understanding in terms of vasorelaxation caused by astragaloside IV and simultaneously contribute to improving and enlarging the clinical application for AM in the field of cardiovascular diseases.

Contractile activity of vascular smooth muscle depends on the concentration alternation of $\left(\mathrm{Ca}^{2+}\right)_{\mathrm{i}}$, which is recruited from the extracellular $\mathrm{Ca}^{2+}$ influx through the activation upon voltage-dependent $\mathrm{Ca}^{2+}$ and receptor-operated $\mathrm{Ca}^{2+}$ and storage $\mathrm{Ca}^{2+}$ release from sarcoplasmic reticulum (22-24). In the study, the action of astragaloside IV in isolated thoracic aortic rings was evidenced to relax the contraction induced by $\mathrm{KCl}$ or PHE in a concentration-dependent manner, suggesting that astragaloside IV may act as a vasospasmolytic. The contractile mechanisms on $\mathrm{KCl}$ are different from PHE. $\mathrm{KCl}$ contracts vascular smooth muscle in response to membrane depolarization and openness of voltage-dependent $\mathrm{Ca}^{2+}(25,26)$, while PHE induces contraction through the activation upon receptor-operated $\mathrm{Ca}^{2+}$ without membrane depolarization $(27,28)$. The results showed that preincubation with astragaloside IV produced significantly depressant effects on contraction stimulated by $\mathrm{KCl}$ or PHE, suggesting that astragaloside IV may be a $\mathrm{Ca}^{2+}$ antagonist and reduces 
Table I. Effects of L-NAME on $\mathrm{E}_{\max }$ and $\mathrm{p} D 2$ values to astragaloside IV treatment in E+ and E- aortic rings pretreated with phenylephrine.

E+

\begin{tabular}{|c|c|c|c|c|}
\hline \multirow[b]{2}{*}{ Treatment } & & \\
\hline & $E_{\max }, \%$ & $\mathrm{p} D 2$ & $E_{\max }, \%$ & $\mathrm{p} D 2$ \\
\hline Astragaloside IV & $100.01 \pm 9.64$ & $1.71 \pm 0.27$ & $82.81 \pm 3.63$ & $1.45 \pm 0.51$ \\
\hline Astragaloside IV + L-NAME & $66.75 \pm 11.05^{\mathrm{a}}$ & $1.17 \pm 0.30^{\mathrm{a}}$ & $64.88 \pm 13.94^{\mathrm{a}}$ & $0.77 \pm 0.16^{\mathrm{a}}$ \\
\hline
\end{tabular}

${ }^{a} \mathrm{P}<0.01$ compared with astragaloside IV acting in E+ or E- arterial rings, respectively. Data are mean \pm standard deviation $(\mathrm{n}=8)$. L-NAME, $\mathrm{N}^{\omega}$-nitro-L-arginine methyl ester; E+, thoracic aortic rings with an endothelium; E-, thoracic aortic rings without an endothelium.

A

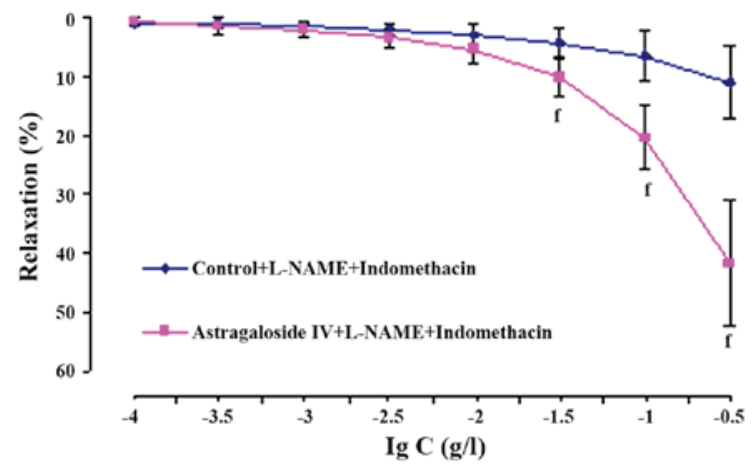

B

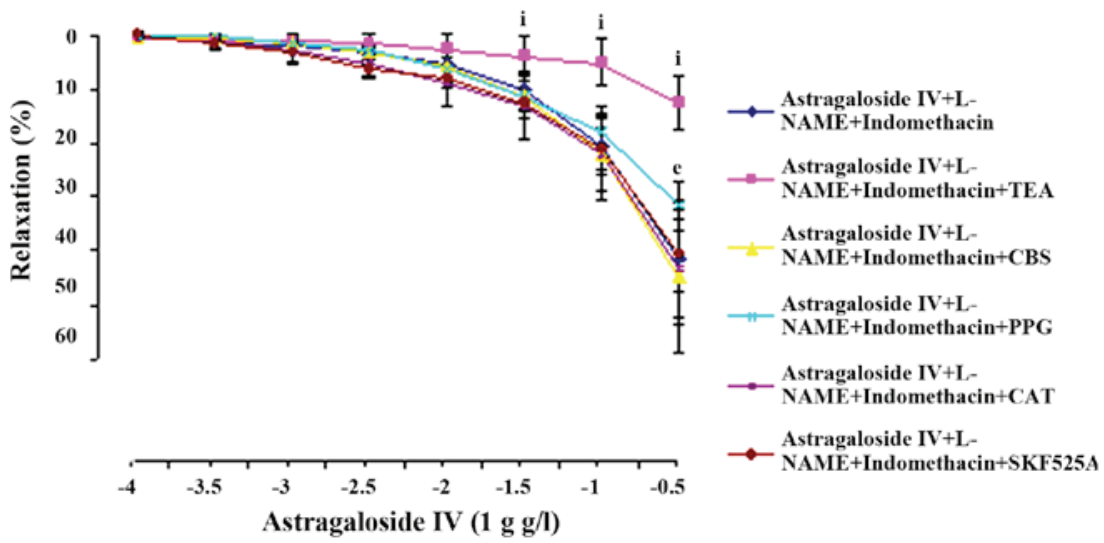

Figure 5. Relaxant effects of astragaloside IV $\left(1 \times 10^{-4}-3 \times 10^{-1} \mathrm{~g} / \mathrm{l}\right)$ on preincubation with (A) L-NAME $(100 \mu \mathrm{M})$ plus indomethacin $(10 \mu \mathrm{M})$ and (B) L-NAME plus indomethacin and TEA $(1 \mathrm{mM}), \mathrm{CBX}(10 \mu \mathrm{M})$, PPG $(100 \mu \mathrm{M})$, CAT $(500 \mathrm{U} / \mathrm{ml})$ or SKF525A $(10 \mu \mathrm{M})$ for 20 min in rat aortic rings after a contraction induced by PHE $(1 \mu \mathrm{M})$. The alternation of tension is expressed as percentage of the active contraction induced by PHE. Data are mean \pm standard deviation $(\mathrm{n}=8) .{ }^{\mathrm{f}} \mathrm{P}<0.01$ compared with vehicle control; ${ }^{\mathrm{e}} \mathrm{P}<0.05,{ }^{\mathrm{i}} \mathrm{P}<0.01$ compared with astragaloside IV plus L-NAME plus indomethacin. PHE, phenylephrine; L-NAME, $\mathrm{N}^{\omega}$-nitro-L-arginine methyl ester; TEA, tetraethtylamine; CBX, carbenoxolone; PPG, propargylglycine; CAT, catalase; SKF525A, proadifen hydrochloride.
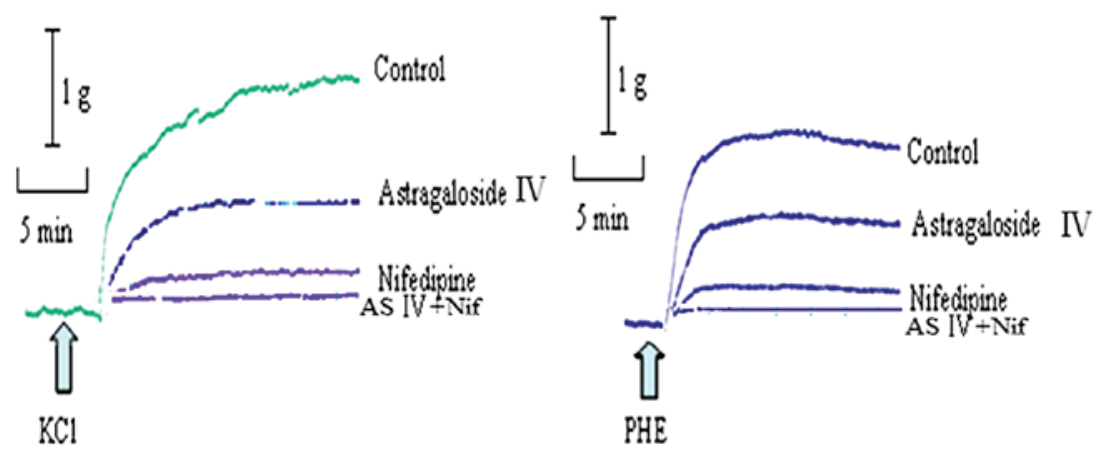

Figure 6. Typical records of inhibitory effects of astragaloside IV (100 mg/l), nifedipine (100 mg/l), and astragaloside IV (100 mg/l) + nifedipine (100 mg/l) on the contraction induced by $\mathrm{KCl}(60 \mathrm{mM})$ or PHE $(1 \mu \mathrm{M})$ in rat aortic rings. AS IV + Nif, astragaloside IV plus nifedipine; PHE, phenylephrine; KCl, potassium chloride. 


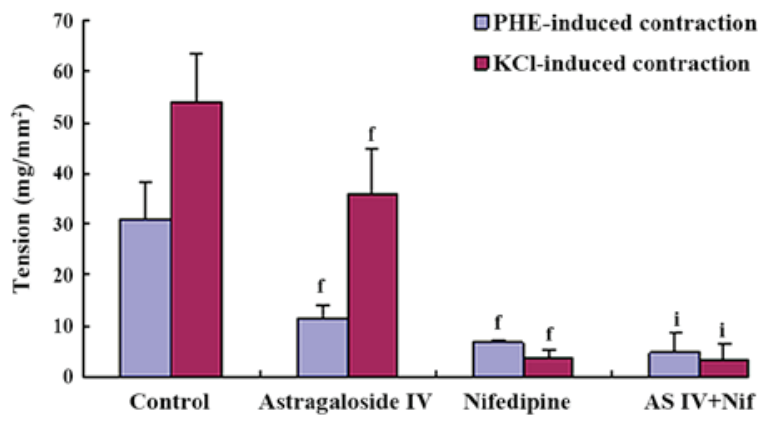

Figure 7. Inhibitory effects of astragaloside IV (100 mg/l), nifedipine $(100 \mathrm{mg} / \mathrm{l})$ and astragaloside IV $(100 \mathrm{mg} / \mathrm{l})+$ nifedipine $(100 \mathrm{mg} / \mathrm{l})$ on the contraction induced by $\mathrm{KCl}(60 \mathrm{mM})$ or $\mathrm{PHE}(1 \mu \mathrm{M})$ in rat aortic rings. Data are mean \pm standard deviation $(\mathrm{n}=8) .{ }^{\mathrm{f}} \mathrm{P}<0.01$ compared with vehicle control, ${ }^{\mathrm{i}} \mathrm{P}<0.01$ compared with astragaloside IV. AS IV + Nif, astragaloside IV plus nifedipine; PHE, phenylephrine; $\mathrm{KCl}$, potassium chloride.

the contractile action via interfering with voltage-dependent $\mathrm{Ca}^{2+}$ and receptor-operated $\mathrm{Ca}^{2+}$, which is in accordance with the previous studies on using $\mathrm{KCl}$ or PHE (18-20) in rat thoracic aortic rings preincubated with astragaloside IV. The inhibitory effects of astragaloside IV on contraction were compared to the contraction caused by nifedipine, a selective L-type $\mathrm{Ca}^{2+}$ channels blocker (29). In various types of smooth muscle, $\mathrm{Ca}^{2+}$ channels blockers strongly decreased high $\mathrm{K}^{+}$-induced increase in $\left(\mathrm{Ca}^{2+}\right)_{\mathrm{i}}(30)$. The present study revealed that astragaloside IV and nifedipine reduced high $\mathrm{K}^{+}$-induced contraction. Simultaneously, the data also revealed that astragaloside IV could also reduce the contraction induced by PHE. These findings indicate that astragaloside IV may block the voltage-dependent $\mathrm{Ca}^{2+}$ and receptor-operated $\mathrm{Ca}^{2+}$ channels, which is distinct from the action mode of nifedipine that mainly blocks voltage-dependent $\mathrm{Ca}^{2+}$ channels. Karaki et al (12) observed that the contraction triggered by the $\alpha 1$ receptor agonist was less sensitive to $\mathrm{Ca}^{2+}$ channels blockers compared to that induced by high $\mathrm{K}^{+}$. However, the present results demonstrated that the inhibitory effect of astragaloside IV on PHE-induced contraction was more potent compared to that on $\mathrm{KCl}$-induced contractile activities, suggesting that astragaloside IV differs from $\mathrm{Ca}^{2+}$ channels blocker. Therefore, astragaloside IV is likely to block the superior receptor-operated $\mathrm{Ca}^{2+}$ channels and inferior voltage-dependent $\mathrm{Ca}^{2+}$ channels. To confirm the attributes of astragaloside IV blocking $\mathrm{Ca}^{2+}$ channels, astragaloside IV and nifedipine were used in combination. The inhibitory effect of the combined use was enhanced, and its actions on $\mathrm{KCl}$-induced contraction were similar to that elicited by PHE. Furthermore, voltage-dependent $\mathrm{Ca}^{2+}$ entry is eliminated in the presence of nifedipine. Therefore, the reinforced depression induced by astragaloside IV appears to be the involvement with receptor-operated $\mathrm{Ca}^{2+}$ channels antagonism. Taken together, astragaloside IV may act as a $\mathrm{Ca}^{2+}$ antagonist through blocking the superior receptor-operated $\mathrm{Ca}^{2+}$ and inferior voltage-dependent $\mathrm{Ca}^{2+}$ channels, but further and sufficient proof is required to verify its characteristics of $\mathrm{Ca}^{2+}$ channels antagonism.

There are two vascular relaxant pathways; endothelium-dependence and -independence. In the present study, although the $E_{\max }$ produced by astragaloside IV in the
E- arterial rings pre-contracted by PHE was significantly declined, no notable changes in the sensitivity $(\mathrm{p} D 2)$ were observed when compared to those in the E+ arterial rings, respectively. The results are consistent with those reported by Wang et al (18) using astragaloside IV in rat $\mathrm{E}+$ and $\mathrm{E}$ - aortic rings precontracted with PHE or high $\mathrm{K}^{+}$solution and with those observed by Zhang et al (20) using astragaloside IV in normal and stroke-prone spontaneously hypertensive rat thoracic aortic rings contracted by PHE, high $\mathrm{K}^{+}$solution or $\mathrm{CaCl}_{2}$, and perivascular fat-intact aortic rings precontracted with PHE or angiotensin II, which suggests that astragaloside IV dilates aortic vessels via endothelium-dependence and -independence.

Vasorelaxation in response to NO converted by its precursor substance L-arginine under the participation in the NOS is frequently considered to be mediated by an increased expression of cGMP in vascular smooth muscle as a result of activation upon sGC. In the pretreatment PHE-induced contractile E+ arterial rings with L-NAME, the $E_{\max }$ and $\mathrm{p} D 2$ values produced by astragaloside IV were significantly reduced. The results indicate that endothelium-derived NO mediates astragaloside IV-induced vasodilatation, which is in accordance with previous studies (18-20). However, NO is not only generated from vascular endothelial cells in the stimulation of bioactive substance, but is also synthesized from VSMC, particularly in the condition of endothelial dysfunction in response to the increments of inflammatory factors (31), oxidative stress (32), obesity and insulin resistance (33). In addition, high content NO (34), secreted by activating the expression of iNOS, is considered harmful to the body although it is able to antagonize vasoconstriction in the form of compensation. In E- arterial rings, endothelium-derived $\mathrm{NO}$ is exhausted. However, preincubation with L-NAME could also significantly reduce the relaxation of astragaloside IV, suggesting that astragaloside IV relaxes aortic vessels, which is through the endothelium-independence and NO signaling pathways. Altogether, NO generation from the vascular endothelial cells and VSMC mediates vasorelaxation of astragaloside IV. However, whether astragaloside IV directly targets at VSMC, which secondly synthesize NO in the presence of endothelial integrity, remains to be elucidated.

EDHFs, as another vasodilator, are crucial to regulate vascular tension and maintain homeostasis. Vasodilatation mediated by EDHFs is considered to be a backup mechanism in case of endothelial dysfunction or insufficient NO, thus the perspective that it is more important than $\mathrm{NO}$ to a certain extent is accepted (17). At present, EDHFs were studied with the common method of adopting preincubation with L-NAME together with indomethacin in order to exclude the interference of $\mathrm{NO}$ and $\mathrm{PGI}_{2}$. In the present study, astragaloside IV also showed a concentration-dependent vasodilatation when the rings exposed to PHE were preincubated with L-NAME and indomethacin, indicating that vasodilatation response to astragaloside IV is independent on $\mathrm{NO}$ and $\mathrm{PGI}_{2}$. These substances were considered to possibly be the EDHFs. Therefore, the arterial rings in the presence of L-NAME plus indomethacin were added to $\mathrm{Ca}^{2+}$-sensitive $\mathrm{K}^{+}$channels blocker TEA, which is a marker used to identify EDHFs. The data revealed that the vasodilatitation was significantly attenuated 
by astragaloside IV, suggesting that astragaloside IV induces endothelium-derived hyperpolarizing reactions. Although numerous studies on EDHFs have been published, thus far the detailed substances on EDHFs have not been identified with potential candidates, including $\mathrm{K}^{+}$, metabolic products of epoxyeicosatrienoic acid (35), hydrogen peroxide (36), hydrogen sulfide $\left(\mathrm{H}_{2} \mathrm{~S}\right)(37)$ and intracellular gap junction (38). To determine which of these substances are possibly responsible for the vasodilatation response to astragaloside IV, in the present study the rings were pretreated with L-NAME plus indomethacin and CBX, PPG, CAT or SKF525A, respectively, following the contraction induced by PHE. The results indicated that the relaxant actions of astragaloside IV were affected by PPG and not by CBX, CAT or SKF525A. This appears to suggest that astragaloside IV-induced vasodilatation is associated with $\mathrm{H}_{2} \mathrm{~S}$ synthesis. Collectively, astragaloside IV promotes endothelial cell secretion of $\mathrm{K}^{+}$and $\mathrm{H}_{2} \mathrm{~S}$, which participate in endothelium-derived hyperpolarizing reactions, and consequently relaxes the vessels.

In conclusion, astragaloside IV has been shown to have direct inhibition on aortic contraction induced by $\mathrm{KCl}$ or $\mathrm{PHE}$ in vitro. Astragaloside IV acts as a $\mathrm{Ca}^{2+}$ antagonist inhibiting the contraction by blockade of superior receptor-operated $\mathrm{Ca}^{2+}$ and inferior voltage-dependent $\mathrm{Ca}^{2+}$ channels. Astragaloside IV relaxes the vessels through endothelium-dependent and -independent NO pathways, and causes vasodilatation in association with $\mathrm{K}^{+}$- and $\mathrm{H}_{2} \mathrm{~S}$-mediated endothelium-derived hyperpolarizing reactions.

\section{Acknowledgements}

The study was financially supported by the Academic and Technical Leaders Training Funds of Sichuan Province in 2014 (grant no. 003099013003).

\section{References}

1. Dong HY, Yang JG, Xiao ZQ, Feng WY, Deng X, Zhang LT and Wei YX: Pro-angiogenic effects of four Chinese medicines and three herbal prescription in chicken chorioallantoic membrane model. Zhong Yao Cai 36: 1297-1300, 2013 (In Chinese).

2. Ji KT, Tang JF and Chai JD: Effect of astragaloside against the oxidative damage on endothelial cells. Zhongguo Zhong Xi Yi Jie He Za Zhi 31: 807-810, 2011 (In Chinese).

3. Qiu YY,Zhu JX, Bian T, Gao F, Qian XF, Du Q, Yuan MY, Sun H, Shi LZ and Yu MH: Protective effects of astragaloside IV against ovalbumin-induced lung inflammation are regulated/mediated by T-bet/GATA-3. Pharmacology 94: 51-59, 2014.

4. Cheng X, Gu J, Zhang M, Yuan J, Zhao B, Jiang J and Jia X: Astragaloside IV inhibits migration and invasion in human lung cancer A549 cells via regulating PKC- $\alpha$-ERK1/2-NF- $\kappa \mathrm{B}$ pathway. Int Immunopharmacol 23: 304-313, 2014.

5. Qi Q, Mao Y, Yi J, Li D, Zhu K and Cha X: Anti-fibrotic effects of Astragaloside IV in systemic sclerosis. Cell Physiol Biochem 34: 2105-2116, 2014

6. Shang L, Qu Z, Sun L, Wang Y, Liu F, Wang S, Gao H and Jiang F: Astragaloside IV inhibits adenovirus replication and apoptosis in A549 cells in vitro. J Pharm Pharmacol 63: 688-694, 2011.

7. Li YR, Cao W, Guo J, Miao S, Ding GR, Li KC, Wang J and Guo GZ: Comparative investigations on the protective effects of rhodioside, ciwujianoside-B and astragaloside IV on radiation injuries of the hematopoietic system in mice. Phytother Res 25 644-653, 2011

8. Shan YH, Peng LH, Liu X, Chen X, Xiong J and Gao JQ: Silk fibroin/gelatin electrospun nanofibrous dressing functionalized with astragaloside IV induces healing and anti-scar effects on burn wound. Int J Pharm 479: 291-301, 2015.
9. Wang SG, $\mathrm{Xu}$ Y, Chen JD, Yang $\mathrm{CH}$ and Chen $\mathrm{XH}$ : Astragaloside IV stimulates angiogenesis and increases nitric oxide accumulation via JAK2/STAT3 and ERK1/2 pathway. Molecules 18: 12809-12819, 2013.

10. Yang QY, Lu S and Sun HR: Effects of astragalus on cardiac function and serum tumor necrosis factor-alpha level in patients with chronic heart failure. Zhongguo Zhong Xi Yi Jie He Za Zhi 30: 699-701, 2010 (In Chinese).

11. Liu KZ, Li JB, Lu HL, Wen JK and Han M: Effects of Astragalus and saponins of Panax notoginseng on MMP-9 in patients with type 2 diabetic macroangiopathy. Zhongguo Zhong Yao Za Zhi 29: 264-266, 2004 (In Chinese).

12. Karaki H, Ozaki H, Hori M, Mitsui-Saito M, Amano K, Harada K, Miyamoto S, Nakazawa H, Won KJ and Sato K: Calcium movements, distribution, and functions in smooth muscle. Pharmacol Rev 49: 157-230, 1997.

13. Taggart MJ, Menice CB, Morgan KG and Wray S: Effect of metabolic inhibition on intracellular $\mathrm{Ca}^{2+}$, phosphorylation of myosin regulatory light chain and force in rat smooth muscle. J Physiol 499: 485-496, 1997.

14. Bełtowski J and Jamroz-Wiśniewska A: Hydrogen sulfide and endothelium-dependent vasorelaxation. Molecules 19: 21183-21199, 2014.

15. Jobe SO, Ramadoss J, Wargin AJ and Magness RR: Estradiol-17 $\beta$ and its cytochrome P450- and catechol-O-methyltransferase-derived metabolites selectively stimulate production of prostacyclin in uterine artery endothelial cells: Role of estrogen receptor- $\alpha$ versus estrogen receptor- $\beta$. Hypertension 61: 509-518, 2013.

16. Mathewson AM and Dunn WR: A comparison of responses to raised extracellular potassium and endothelium-derived hyperpolarizing factor (EDHF) in rat pressurised mesenteric arteries. PLoS One 9: e111977, 2014.

17. Xavier FE, Blanco-Rivero J, Sastre E, Caracuel L, Callejo M and Balfagón G: Tranilast increases vasodilator response to acetylcholine in rat mesenteric resistance arteries through increased EDHF participation. PLoS One 9: e100356, 2014.

18. Wang QH, Zhu L and Chen H: Effect of astragaloside IV on thoracic aortic rings isolated from fat. Chin Pharmacol Bull 22: 1319-1323, 2006.

19. Zhang C, Wang XH, Zhong MF, Liu RH, Li HL, Zhang WD and Chen H: Mechanisms underlying vasorelaxant action of astragaloside IV in isolated rat aortic rings. Clin Exp Pharmacol Physiol 34: 387-392, 2007.

20. Zhang WD, Zhang C, Wang XH, Gao PJ, Zhu DL, Chen H, Liu RH and Li HL: Astragaloside IV dilates aortic vessels from normal and spontaneously hypertensive rats through endothelium-dependent and endothelium-independent ways. Planta Med 72: 621-626, 2006.

21. Wang KH: Aqueous extracts from Chinese herb Ginseng, Astragalus membranaceus and Scutellaria baicalensis increase the expression both NO and cGMP. Foreign Med Sci 18: 38-39, 1996.

22. Hamada H, Damron DS, Hong SJ, Van Wagoner DR and Murray PA: Phenylephrine-induced $\mathrm{Ca}^{2+}$ oscillations in canine pulmonary artery smooth muscle cells. Circ Res 81: 812-823, 1997.

23. Su X, Smolock EM, Marcel KN and Moreland RS: Phosphatidylinositol 3-kinase modulates vascular smooth muscle contraction by calcium and myosin light chain phosphorylation-independent and -dependent pathways. Am J Physiol Heart Circ Physiol 286: H657-H666, 2004.

24. Carmignoto G, Pasti L and Pozzan T: On the role of voltage-dependent calcium channels in calcium signaling of astrocytes in situ. J Neurosci 18: 4637-4645, 1998.

25. Ratz PH and Berg KM: 2-Aminoethoxydiphenyl borate inhibits $\mathrm{KCl}$-induced vascular smooth muscle contraction. Eur J Pharmacol 541: 177-183, 2006.

26. Kravtsov GM and Kwan CY: A revisitation on the mechanism of action of KCl-induced vascular smooth muscle contraction: A key role of cation binding to the plasma membrane. Biol Signals 4: 160-167, 1995.

27. Lee CH, Poburko D, Sahota P, Sandhu J, Ruehlmann DO and van Breemen $C$ : The mechanism of phenylephrine-mediated $[\mathrm{Ca}(2+)](\mathrm{i})$ oscillations underlying tonic contraction in the rabbit inferior vena cava. J Physiol 534: 641-650, 2001.

28. Hirata S, Enoki T, Kitamura R, Vinh VH, Nakamura $\mathrm{K}$ and Mori K: Effects of isoflurane on receptor-operated $\mathrm{Ca}^{2+}$ channels in rat aortic smooth muscle. Br J Anaesth 81: 578-583, 1998 . 
29. Sensch O, Vierling W, Brandt W and Reiter M: Effects of inhibition of calcium and potassium currents in guinea-pig cardiac contraction: Comparison of beta-caryophyllene oxide, eugenol, and nifedipine. Br J Pharmacol 131: 1089-1096, 2000.

30. Muraki K, Bolton TB, Imaizumi Y and Watanabe M: Effect of isoprenaline on $\mathrm{Ca}^{2+}$ channel current in single smooth muscle cells isolated from taenia of the guinea-pig caecum. J Physiol 471: 563-582, 1993

31. Denis MC, Furtos A, Dudonné S, Montoudis A, Garofalo C, Desjardins Y, Delvin E and Levy E: Apple peel polyphenols and their beneficial actions on oxidative stress and inflammation. PLoS One 8: e53725, 2013.

32. Zhang M, Sun S, Tang N, Cai W and Qian L: Oral administration of alkylglycerols differentially modulates high-fat diet-induced obesity and insulin resistance in mice. Evid Based Complement Alternat Med 2013: 834027, 2013.

33. Bak MJ, Hong SG, Lee JW and Jeong WS: Red ginseng marc oil inhibits iNOS and COX-2 via NFKB and p38 pathways in LPS-stimulated RAW 264.7 macrophages. Molecules 17: 13769-13786, 2012.

34. Ayele Y, Kim JA, Park E, Kim YJ, Retta N, Dessie G, Rhee SK, Koh K, Nam KW and Kim HS: A methanol extract of Adansonia digitata $\mathrm{L}$. leaves inhibits pro-inflammatory iNOS possibly via the inhibition of NF- $\mathrm{kB}$ activation. Biomol Ther (Seoul) 21: $146-152,2013$
35. Campbell WB and Gauthier KM: Inducible endothelium-derived hyperpolarizing factor: Role of the 15-lipoxygenase-EDHF pathway. J Cardiovasc Pharmacol 61: 176-187, 2013.

36. Garry A, Edwards DH, Fallis IF, Jenkins RL and Griffith TM: Ascorbic acid and tetrahydrobiopterin potentiate the EDHF phenomenon by generating hydrogen peroxide. Cardiovasc Res 84: 218-226, 2009.

37. Jamroz-Wiśniewska A, Gertler A, Solomon G, Wood ME, Whiteman $M$ and Bełtowski J: Leptin-induced endothelium-dependent vasorelaxation of peripheral arteries in lean and obese rats: Role of nitric oxide and hydrogen sulfide. PLoS One 9: e86744, 2014.

38. Fujiwara H, Wake Y,Hashikawa-Hobara N, Makino K, Takatori S, Zamami Y, Kitamura Y and Kawasaki H: Endothelium-derived relaxing factor-mediated vasodilation in mouse mesenteric vascular beds. J Pharmacol Sci 118: 373-381, 2012. 